\title{
Violence against women in Nepal: Role of health care workers
}

\author{
Joshi SK \\ Assistant Professor, Department of Community Medicine, Kathmandu Medical College, Sinamangal, Nepal
}

$\mathrm{V}$ iolence against Women (VAW) is one of the most pervasive of human rights violations, denying women and girl's equality, security, dignity, self-worth, and their right to enjoy fundamental freedoms. Violence against women is present in every country, cutting across boundaries of culture, class, education, income, ethnicity and age. Violence against women is actually violence against mothers, sisters, wives, daughters and daughter-in-laws. According to $\mathrm{UNICEF}^{1}$ there exist six kinds of violence against women and girls in South Asia, mainly (i) sexual abuse, (ii) incest and rape by family members and other, (iii) recruitment by family members into prostitution, (iv) neglect by family members, even to the point of death, (v) feticide and infanticide, (vi) dowry demand and wife abuse.

Most perpetrators of domestic violence escape persecution under the Nepali criminal justice system. Many cases are found where perpetrators of domestic violence escape persecution due to ineffective criminal law of Nepal. Population Briefs, a newsletter of the Population Council ${ }^{2}$, reports a high level of physical abuse in homes among pregnant women in Nepal. The maternal mortality study conducted by Family Health ${ }^{3}$, revealed the higher suicide rate among women of reproductive age group. Fifty eight percent of women who suffered domestic violence confirmed daily abuse ${ }^{4}$. Similarly, a survey ${ }^{5}$ among the health professionals revealed that domestic violence has been reported to result in high maternal death, preterm birth and high prenatal mortality, abortion, miscarriage and impact on long term health of women. In addition to causing injury, violence increases women's long-term risk of a number of other health problems, including chronic pain, physical disability, drug and alcohol abuse, and depression. Backache, problem in vision and poor subjective health were common physical health problems.

Trafficking of girls/women is another gross violation of the human right and a serious form of VAW. The trafficking of girls/women from Nepal into India and Middle East takes place mainly for the purpose of prostitution. Trafficking in women and girls is easy along the 1,740 mile-long open border between India and Nepal. At least 26 districts of Nepal are considered as areas that have high occurrence of trafficking, and the Ministry of Women, Children, and Social Welfare provided small grants to task forces in those high-risk districts to raise awareness and mobilize communities against trafficking. Similarly, NGOs cite a growing internal child sex tourism problem, with an estimated 5,000 to 7,000 girls trafficked from rural areas to Kathmandu for commercial sexual exploitation ${ }^{6}$. Maiti Nepal is a National led NGO working on rescue of victims of trafficking at the border between Nepal and India and from the brothels in India as well. Such victims of abuse and rescued women from the brothels are being provided shelter in a rehabilitation centre operated by them. Most of those women are suffering from HIV infection and are shunned by own families

Domestic VAW are underreported in our country, and the reasons behind underreporting are to save family prestige, and privacy, fear of husband and mother in-law, love and affection with husband and family members, fear of breaking family relation, fear of social traditional and socio-cultural values, fear of further beating, physically assault, marginalization, uncertainty of justice, lack of faith in justice and support of other. Men use threats of abandonment, seeking sexual gratification elsewhere, remarriage and quarrel to force sex upon wives early in marriage. As a result, for most present generation women, married life means depression, mental torture, self immolation; bride burning for dowry demand.

Wife battering is covered by Domestic Violence Act entitled "Legislation to Control and Manage Domestic Violence 2009" in Nepal. The Women's Rights Division of Human Rights Watch fights against the dehumanization and marginalization of women with solidarity to end traditions, practices, and laws that harm women. Although the Interim Constitution does not allow discrimination based on sex, caste, creed or colour there are more than 150 discriminatory provisions against women in the forms of denial access to and control over resources, restricted mobility, low representation in decision-making positions in civil services, politics and public sectors, lack of opportunities for advancement and the attendant problems resulting in longer working 
hours, illiteracy, poor health, high maternal mortality rates, increasing number of trafficking of women and girls, violence against women and girls, witch-hunting and so on. In the absence of proper legal protection, many widows and women in rural Nepal are often accused of practicing witchcraft, beaten, paraded naked and forced to eat excreta by illiterate and superstitious villagers. As we have no specific law to deal with such evil acts, they are dealt with under the Public Offense Act, and the District Administration Offices let off perpetrators of such crimes after imposing some fines. We hope the new Constitution of Republic of Nepal will be able to encompass the lacking issues in the previous constitution.

In Nepal, health care providers are still likely to be the first point of contact between a woman in difficulty and the formal health care system, and as such constitute a frontline of identification and intervention. Usually, such women present at the hospital or clinics with other somatic problems, and try not to mention about violence. Providing a supportive, violence-aware practice environment, using sympathetic and empowering language that is appropriate to each patient, knowing how to conduct a physical examination to confirm physical / sexual assault, and being aware of local services to which women who are abused can be referred as an important steps towards its prevention. It is very important that they know how to provide thorough treatments of not only the physical consequences of abuse but also the mental health sequel, including post-traumatic stress disorder. The consulting physicians should consider treatment of the abuse of women as a complex, multidimensional clinical problem and its provision of specific practical suggestions and resources relevant to the continuum of care, from identification to diagnosis, immediate intervention, and long-term management. It does not mean that all women who come to health care settings should be asked about abuse, whether or not there are clinical indications of violence.

There are many screening tools available for various settings, and for pregnant women. Examples of few such available tolls are Conflict Tactics Scale (CTS \& CTS-2), Composite Abuse Scale (CAS), Partner Violence Screen (PVS), Index of Spouse Abuse (ISA), Woman Abuse Screening Tool (WAST), Abuse Assessment Screen (AAS) (for pregnant women). Many doctors use such tools reasonably well in identifying women who have been abused. If they suspect of abuse, interventions, such as counselling in the primary care setting, referral of women for expert counselling, referral to a safe place or community resources are important. Sometimes, referral of batterers/couples for expert counselling yields good results. However, in our country post intervention studies to measure the reduction in abuse are almost lacking. Experiences from other countries shows mixed results in term of shelter effectiveness, less physical reabuse, improved quality of life, increased use of social support, increased effectiveness in obtaining resources ${ }^{7}$. We should also think about potential harms that might arise from such interventions. For example, involvement of child protection agency or women rights groups in the business may put the children and women at greater risk from the abuser. Sometime there is reprisal of abuse against those women who return home from shelters, and to prevent that structured post-shelter advocacy counselling is effective in reducing re-abuse. VAW is a complex issue and needs attention from wide range of authorities. The role of clinicians is also complex, starting from the screening of the problem until the long term rehabilitation. At the end, I would like to state a fact that there is insufficient evidence to recommend for or against routine universal screening for violence against either pregnant or non-pregnant women, however clinicians should be alert to signs and symptoms of potential abuse and may wish to ask about exposure to abuse during diagnostic evaluation of these patients ${ }^{8}$.

\section{References}

1. UNC Fund. Domestic Violence against Women and Girls. Innocenti Digest. 2000; 6.

2. Population Council. Violence against Women. Population Briefs. 2005; 11( 3).

3. Pathak LK, Malla D, Pradhan A, Rajlawat R. Maternal mortality and morbidity study. Nepal: Family Health Division, Department of Health Services.1998.

4. SAATHI. The Situational Analysis of Violence against Women and Girls in Nepal. Kathmandu: SAATHI. 1997.

5. Samanata. Linkage between Domestic Violence and Pregnancy. Kathmandu: Samanata. 2005.

6. United States Department of State. Trafficking in Persons Report 2008 - Nepal, 4 June 2008 [homepage on the internet]. available at: http:// www.unhcr.org/refworld/docid/484f9a2fc.html

7. Sullivan CM. Bybee DI. Reducing violence using community-based advocacy for women with abusive partners. Journal of consulting and clinical psychology. 1999; 67(1):43-53.

8. Wathen $\mathrm{CN}$, MacMillan HL. Prevention of violence against women: Recommendation statement from the Canadian Task Force on Preventive Health Care. CMAJ. 2003; 169(6):582-4. 